\title{
Appraisal of National Response to Chronic Hepatitis in Pakistan
}

\author{
Amimah Fatima Asif ${ }^{1}$, Rana Hussain Asif ${ }^{2}$, Rana Haider Asif ${ }^{3}$ \\ ${ }^{1}$ Medical Officer, DHQ Hospital Nankana Sahib \\ 2 Research Fellow, Baptist Health System, South Florida USA \\ ${ }^{3}$ Research Assistant, Baptist Health System, South Florida USA
}

\begin{abstract}
Chronic hepatitis has emerged as a grave health crisis in Pakistan that is becoming increasingly difficult to control. The national response in the public and private sector is lacking realism, direction and strategy. The aim of the present review was to analyze the efforts directed towards elimination of this menace, outline the challenges and make pragmatic recommendations. We searched PubMed, Google Scholar and Google web search for relevant indexed literature in English using the Mesh terms 'Chronic Hepatitis', 'Pakistan', 'Hepatitis B', 'Hepatitis C', 'Hepatitis prevention', 'National hepatitis control', etc. Rigorous efforts to improve the capacity of the primary healthcare establishments are pivotal to contain further spread of hepatitis $B$ and $C$ infections. Combating quackery, regulating the use of medical sharps and making affordable hepatitis treatment accessible to the masses should be the principal focus of the government. Healthcare delivery units should be equipped to render complete coverage of essential quality hepatitis services in order to curb this menace.
\end{abstract}

Key words: Hepatitis B, Hepatitis C, Pakistan

Authors' Contribution:
1,2 Conception, synthesis, planning of
research and manuscript writing
Interpretation and discussion
Data analysis, interpretation and manuscript
writing, ${ }^{3}$ Active participation in data
collection.

Cite this article. Asif AF, Asif RH, Asif RH. Appraisal of National Response to Chronic

Hepatitis in Pakistan. J Islamabad Med Dental Coll.2019; 8(1):3-7
Amimah Fatima Asif

Email: amimahfasif@hotmail.com

\author{
Article info: \\ Received: January 17, 2019 \\ Accepted: February 6, 2019
}

\section{(1)}


for prevention of hepatitis B viral infection while there is no vaccine available for hepatitis $C$ viral infection.

Globally, hepatitis caused 1.54 million deaths in 2013, showing a substantial increase from 0.89 million deaths in 1990. The increase in morbidity was noted in the form of years lived with disability from 0.65 million in 1990 to 0.87 million in 2013 and disability adjusted life years (DALY) from 31.7 million in 1990 to 42.5 million in 2013. Hepatitis $B$ and $C$ are the cause of $96 \%$ mortality and $91 \%$ of DALYs in 2013 because they are chronic infections that deteriorate liver function and can potentially cause multi organ failure ${ }^{8}$ According to World Health Organization, worldwide the highest mortality due to hepatitis (i.e. $\geq 33.5$ deaths per 100000 population per year) is in the regions of Oceania, western sub-Saharan Africa and South Asia. Within the Eastern Mediterranean region, Pakistan and Egypt bear $80 \%$ of disease burden due to hepatitis. ${ }^{9}$

This is a review article that is corroborating Pakistan's disease burden due to chronic hepatitis. It aims to analyze the efforts being employed to eliminate hepatitis $B$ and $C$ infections, debunk the actual challenges hindering their elimination and make pragmatic recommendations. We searched PubMed, Google Scholar and Google web search for relevant literature. We used the Mesh terms 'Chronic Hepatitis', 'Pakistan', 'Hepatitis B', 'Hepatitis C', 'Hepatitis prevention', 'National hepatitis control', etc. The main aim of this literature search was to put in perspective the situation of chronic hepatitis in Pakistan and the response of the government to this threat. Articles relating to the prevalence, modes of transmission, risk factors and various community level interventions including both governmental and non-governmental response were included in this desk review. Journal articles, government reports, non-government organization (NGO) reports, newspaper articles, information and reports published by international organizations were retrieved from January 2000 to January 2019. Data was also retrieved from Government of Pakistan's National Hepatitis Control Program and other relevant bodies.

\section{National Hepatitis Control Measures}

In order to restrain the burden of chronic hepatitis, efforts are being undertaken in the public and private sector of Pakistan. Preventive measures which include ensuring immunization of children for hepatitis $B$ through the
Expanded Program of Immunization (EPI) schedule, blood screening for safe blood transfusions, free hepatitis testing and treatment facilities are being taken by the government, private sector and international organizations. But these prevention strategies are lacking complete coverage; moreover, certain crucial initiatives are not being targeted and implemented.

Free hepatitis testing and treatment services are being provided in government hospitals of the four provinces of Pakistan through the provincial hepatitis prevention and control program, however currently there is no integrated national hepatitis control program. ${ }^{10}$ In a public-private partnership endeavor the Government of Punjab has collaborated with the Pakistan Kidney and Liver Institute (PKLI) to provide free testing service and free treatment to deserving patients. This program has expanded to 25 districts of the province of Punjab. ${ }^{11}$

Pakistan Health Research Council (PHRC, previously PMRC) has developed the National Hepatitis Strategy Framework which is a 5-year plan (2017 to 2021) with the goal to eliminate hepatitis by 2030. This plan has a target to reduce $\mathrm{HBV}$ and $\mathrm{HCV}$ related deaths by $10 \%$ and new cases of infection by 30\%.12 The new Direct Acting Antivirals (DAAs) are now approved by international drug regulatory authorities such as Food and Drug Administration (FDA) but the cost of these breakthrough drugs was extremely high which was a major barrier to access. After negotiating with 14 pharmaceutical companies the Ministry of National Health Services, Regulations and Coordination (NHRC) registered generic and branded DAAs.

In 2017, Direct Acting Antiviral (DAA) drug sofosbuvir $400 \mathrm{mg}$ was available for the treatment of Hepatitis $C$ at US $\$ 15$ which is the lowest price in the world. ${ }^{13}$ This drug is being procured by provincial hepatitis control programs to dispense free of cost to non-affording patients. According to WHO, $95 \%$ of people infected with hepatitis $C$ can be cured within 2-3 months with the new oral drug treatment. ${ }^{14}$ It seems evident that the epicenter of efforts by public and private health sector is on treatment of chronic hepatitis, but limited work is being done to address the root causes that are leading to uncontrolled infection transmission and spread in communities. Focus on containing the infection reservoirs through 
implementation of disease prevention techniques, screening and early diagnosis are not the priorities.

\section{Overcoming Challenges in Hepatitis Control}

Due to the frail primary healthcare set up of Pakistan the enforcement and implementation of strategies for disease prevention is one of the key challenges in stifling the spread of hepatitis infection. Screening of high-risk groups and timely diagnosis of hepatitis are the stepping stones of primary care delivery. According to statistics, 7 million people are infected with hepatitis $C$ in Pakistan but only 1 million (14\%) of them are diagnosed. Approximately 4 million people are infected with hepatitis B but only 0.1 million (3\%) of them are diagnosed. ${ }^{15}$ Delayed diagnosis leads to complications such as chronic liver disease, liver cirrhosis and hepatocellular carcinoma. Managing these complications in tertiary care hospitals is expensive, which is an additional burden on the economy of the country.

The government needs to focus on strengthening the primary healthcare delivery points; Basic Health Units (BHU), Rural Health Centers (RHC) and Tehsil Headquarters hospitals (THQ) by promoting hepatitis prevention through community outreach campaigns, encouraging disease screening and providing rapid hepatitis testing kits. It is at these primary cares set ups that infected individuals in the catchment population can be identified and family mapping can be done to identify undiagnosed cases. Proper documentation and follow up are crucial in slowing the spread of infection and the progression of the disease. Additionally, efforts need to be galvanized for ensuring that every child is immunized for hepatitis B. Babies who are not delivered in a healthcare unit, and are home-delivered in villages, are not receiving the hepatitis $B$ vaccination. It is critical to ensure that every new born is immunized as per the EPI schedule which includes the vaccination for hepatitis B (Figure 1).

Although all adult population should be vaccinated for hepatitis $B$ but coverage is inadequate particularly in high risk groups such as sex workers, transgender population, drug addicts and thalassemia patients. ${ }^{16}$

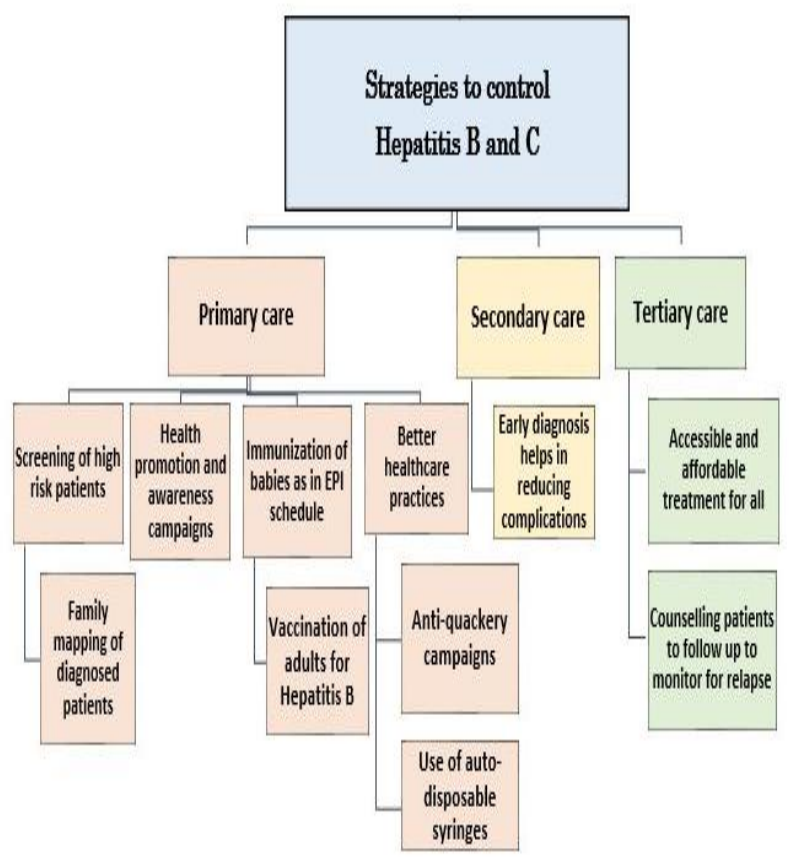

Figure 1. Recommended steps to control spread of Hepatitis B and $C$ infection

Interestingly, the major risk factor for hepatitis transmission in developed countries is intravenous drug use while in Pakistan it is the reuse of syringes for unwarranted therapeutic purposes. ${ }^{17}$ According to a survey by Pakistan Medical Research Council, $48 \%$ of Pakistan's population is taking less than 5 injections per year, $22 \%$ are taking between $5-10$ injections and $6 \%$ are taking over 10 injections per person per year. ${ }^{18}$ The Ministry of National Health Services has introduced auto disabled syringes to eliminate the reuse of syringes in health facilities and by IV drug abusers. ${ }^{19}$ But unfortunately they are not being used in government hospitals and other health facilities. Ensuring the use of auto disabled syringes and regulating their supply is needed to put an end to this major mode of spread for hepatitis infection (Figure 1). Furthermore, there is no proper guideline and training of staff to manage sharp waste disposal and medical waste disposal in public hospitals. ${ }^{20}$

Another significant challenge in the spread of hepatitis is that of quackery in urban and rural areas (Figure 1). A survey conducted in 2014 showed that there are 200,000 quacks working in Pakistan. ${ }^{21}$ The reuse of syringes and lack of sterilization in quack clinics including dental clinics are key causes of spread of hepatitis infections in the 
masses. The government should take the local district authorities in confidence and conduct crackdown on the quack clinics. In addition to this curbing the patient influx in these quack clinics is the responsibility of doctors working in public and private sector to educate patients about the substandard and fraudulent medical practices of quacks. Counseling the patients and their families that seeking treatment from these quacks will put their health at serious risk of contracting harmful infections can prove to be very beneficial and reformative. Quacks are notorious for administering unwarranted intravenous steroids and antibiotics, such subpar treatment regimens lead to spread of infectious diseases and cause antibiotic resistance.

In Pakistan, pegylated interferon-based therapy is being used since the past 10 years for managing hepatitis. The new direct acting antiviral drugs such as Sofosbuvir is now being used and has shown promising results. ${ }^{22}$ There is an urgent need to speed up the registration and availability of new direct acting antivirals for hepatitis in the local market.

With the current state of affairs, the national response to hepatitis control is unsatisfactory and the prospects of eliminating hepatitis by 2030 are bleak. Understanding that there is an emergent need to divert attention to the core public health issues, in order to reduce morbidity and mortality due to hepatitis in Pakistan is of monumental importance. Only the government's unfaltering commitment and sound financial investment in this cause can pave the way for hepatitis elimination in Pakistan.

Pakistan has a major epidemic of chronic hepatitis B and $C$. The high prevalence and the unchecked spread of infection through multiple modes of transmissions is a serious threat. In recent years Pakistan has even been called a "Cirrhotic State", which tells a lot about the country's disease landscape. The lack of awareness of general public, poorly regulated and unhygienic health practices, poor health services and a reactionary approach by the government, all add up to make Pakistan a perfect incubator for not only chronic hepatitis but also other diseases that share similar modes of transmission. Robust preventive and curative interventions which are resistant to the constantly changing socio-political environment of Pakistan are imperative to limit the spread of these chronic ailments and their complications.

\section{References}

1. Al Kanaani Z, Mahmud S, Kouyoumjian SP, AbuRaddad LJ. The epidemiology of hepatitis $C$ virus in Pakistan: systematic review and meta-analyses. $R$ Soc Open Sci. 2018;5(4):180257.

2. Ali SA, Donahue RM, Qureshi H, Vermund SH. Hepatitis B and hepatitis C in Pakistan: prevalence and risk factors. Int J Infect Dis. 2008;13(1):9-19.

3. World Health Organization. WHO urges governments to act on hepatitis threat [Internet]. Who.int. 2019 [cited 2 January 2019]. Available from: https://www.who.int/mediacentre/news/releases/2013/ hepatitis_threat_20130724/en.

4. Moin A., Fatima H., Qadir FT. Tackling hepatitis CPakistan's road to success. Lancet. 2018;391(10123):834-835.

5. Waheed M. World Health Organization-Eastern Mediterranean Office. Prevention and control of hepatitis. Pakistan [Internet]. Emro.who.int. 2019 [cited 4 January 2019]. Available from: http://www.emro.who.int/pak/programmes/preventiona-control-of-hepatitis.html.

6. Bosan A., Qureshi H., Bile KM, et al. A review of hepatitis viral infections in Pakistan. J Pak Med Assoc. 2010;60(12):1045-1058.

7. Khan AJ, Luby SP, Fikree F, Karim A, Obaid S, Dellawala $S$,et al, Unsafe injections and the transmission of hepatitis $B$ and $C$ in a periurban community in Pakistan. Bull World Health Organ 2000; 78: 956-63

8. Wiktor SZ1, Hutin YJ2. The global burden of viral hepatitis: better estimates to guide hepatitis elimination efforts. Lancet. 2016;388(10049):10301031.

9. Fikri M. Eliminating hepatitis from the Eastern Mediterranean Region. East Mediterr Health J-World Health Organization. 2017;23(7):459-460.

10. Waheed M. WHO EMRO. Prevention and control of hepatitis. Pakistan [Internet]. Emro.who.int. 2019 [cited 7 January 2019]. Available from: http://www.emro.who.int/pak/programmes/preventiona-control-of-hepatitis.html.

11. World Health Organization. Fighting hepatitis in Pakistan [Internet]. Who.int. 2019 [cited 8 January 2019]. Available from: https://www.who.int/news- 
room/feature-stories/detail/pakistan-tackles-highrates-of-hepatitis-from-many-angles

12. Health Minister Saira Afzal Tarar addresses World Hepatitis Summit - shares progress in fight against the disease. [Internet]. Ministry of National Health Services, Regulations and Coordination, Government of Pakistan. 2019 [cited 9 January 2019]. Available from:

http://www.nhsrc.gov.pk/press_release_detailes7468. html?pr_id=241.

13. Optimizing medicines and treatment regimens for hepatitis C patients in Pakistan. [Internet]. Worldhepatitissummit.org. 2019 [cited 10 January 2019]. Available from: http://www.worldhepatitissummit.org/docs/defaultsource/posters/4a_dr-hassanmahmood.pdf?sfyrsn=2.

14. Global hepatitis report, 2017. World Health Organization; Geneva 2017.

15. World Health Organization. Hepatitis C [Internet]. Who.int. 2019 [cited 10 January 2019]. Available from: $\quad$ https://www.who.int/news-room/factsheets/detail/hepatitis-c.

16. Memon AR, Shafique K, Memon A, Draz AU, Rauf MU, Afsar $S$. Hepatitis $B$ and $C$ prevalence among the high-risk groups of Pakistani population. A cross sectional study. Arch Public Health. 2012;70(1):9.
17. Moin A., Fatima H., Qadir FT. Tackling hepatitis CPakistan's road to success. Lancet. 2018;391(10123):834-835.

18. Prevalence of hepatitis $B$ and $C$ in Pakistan. Phrc.org.pk. 2019 [cited 10 January 2019]. Available from: http://phrc.org.pk/assets/hepatitis-nationalsurvey.pdf.

19. Janjua NZ, Butt ZA, Mahmood B, Altaf A. Towards safe injection practices for prevention of hepatitis $C$ transmission in South Asia: Challenges and progress. World J Gastroenterol. 2016;22(25):5837-52.

20. Kumar R., Khan EA., Ahmed J, et al. Healthcare Waste Management (HCWM) In Pakistan: Current Situation and Training Options. J Ayub Med Coll Abbottabad 2010;22(4):101-106

21. Ilyas F. Experts demand implementation of healthcare law to end quackery [Internet]. DAWN.COM. 2019 [cited 11 January 2019]. Available from: https://www.dawn.com/news/1439641.

22. Waheed $Y$, Siddiq M. Elimination of hepatitis from Pakistan by 2030: is it possible? Hepatoma Research. 2018;4(8):45. 